\title{
Stressful lie events in alopecia areata patients: A case control study
}

\author{
Rim Sellami ${ }^{1}$, Inès Féki ${ }^{1}$, Rim Masmoudi', Salma Hentati ${ }^{1}$, Hamida Turki², Jawaher Masmoudi \\ ${ }^{1}$ Department of Psychiatry, University Hospital of Sfax, Tunisia, ${ }^{2}$ Department of Dermatology, University Hospital of Sfax, Tunisia \\ Corresponding author: Dr. Rim Sellami, E-mail: rim.sellami@laposte.net
}

\begin{abstract}
Background: The possibility of influence of stress especially of stressful life events on the course of alopecia areata has long been postulated. Objective: The aim of our study was to evaluate the relationship between stressful situations and the onset/ exacerbation of alopecia areata. Methods: Fifty patients with Alopecia Areata seen in the Department of Dermatology were included in this study. The design was a case-control study. Stressful events were evaluated using Holmes and Rahe's social readjustment rating scale. Severity of alopecia areata was measured by Severity of Alopecia Tool. Results: Mean age was $30.84 \pm 10.70$ years. The majority of patients identified stressful events, compared to $56 \%$ of subjects in the control group $(\mathrm{p}=0.003)$. The most important matters in the alopecia areata group were related to personal problems $(\mathrm{p}=0.015)$ and financial problems $(\mathrm{p}=0.010)$. Conclusion: Stress seems to play an important role in the onset and aggravation of alopecia areata.
\end{abstract}

Key words: Alopecia areata; Stress; Life events

\section{INTRODUCTION}

Alopecia areata (AA) is a chronic, inflammatory and autoimmune disease, presenting with non-scarring hair loss [1]. It is a skin disease of unknown etiology with prevalence of $0.2 \%$ in the general population [2]. The aethiopathogenesis of AA is unclear and many factors including the patient's genetic constitution, the atopic state, emotional and environmental stress are claimed to be involved in its development [3-5]. The role of stressful life events in triggering or exacerbating of alopecia areata was apparently clearer [6,7]. Nevertheless, the specific pathogenic role of psychological stress remains unknown $[5,8]$.

The purpose of our study was to evaluate the relationship between stressful situations and the onset/ exacerbation of alopecia areata.

\section{MATERIALS AND METHODS}

All new patients diagnosed with AA and who did not have any previous episodes of AA seen in the
Department of Dermatology of Hedi Chaker University Hospital Sfax between March 2016 and July 2016 were included in the study. Informed consent was obtained from all enrolled subjects. The diagnosis of AA was made by a qualified dermatologist on a clinical basis. Socio demographic and clinical data including age, sex, family history of AA, site of onset and associated diseases were recorded for all patients. Included patients underwent full clinical examination to determine the number and extension of the sites affected by AA and the severity of the disease. The control group included 50 healthy adults recruited from the hospital staff who did not currently or previously have any psychiatric and dermatological disorders. The controls were age-and gender-matched and did not work in an area related to psychiatry or psychology.

Holmes and Rahe's social readjustment rating scale [9] was used for both cases and controls; events occurring during the year before the evaluation were included and those occurring after the onset or exacerbation were excluded. Susceptibility to illness and mental health problems can be influenced by increase in stress levels

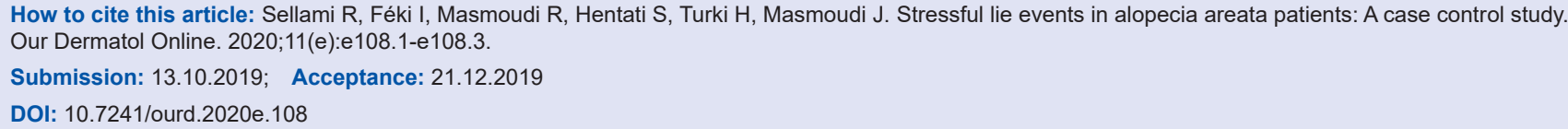


caused by life events. We divided situations described in Holmes and Rahe's scale into three groups: family matters, personal problems, and job or financial problems.

The severity of hair loss was assessed by measuring the percentage of the alopecic area on the scalp. Patients with AA were evaluated using Severity of Alopecia Tool (SALT) [10]. The SALT score is computed by measuring the percentage of hair loss in each of 4 areas of the scalp (40\% vertex, $18 \%$ right profile, $18 \%$ left profile, $24 \%$ posterior) and adding the total to achieve a composite score. Patients were divided according to disease severity: S1-S2: Hair loss below 50\%; S3-S4: Hair loss of 50-99\%; S5: Total scalp hair loss.

\section{RESULTS}

Fifty patients were included in this study. Their mean age was 30.84 years $($ Standard Deviation $=10.70)$, with a minimum of 18 years and a maximum of 57 . There were $48 \%$ males and $52 \%$ females, with a male to female ratio of 0.92 . As to the level of education, $20 \%$ had elementary school education, $38 \%$ had secondary school education, and $42 \%$ had higher education level. $50 \%$ of patients were single, $46 \%$ were married and $4 \%$ were divorced. As to occupation, $52 \%$ were employed, $22 \%$ were unemployed, $24 \%$ were studying and $2 \%$ were retired.

At the time of first presentation, $80 \%$ had patchy alopecia with less than $50 \%$ involvement (S1-S2), 12\% had patchy alopecia with 50-99\% involvement (S3-S4), and $8 \%$ had alopecia total is. The mean duration of hair loss prior to diagnosis was 69.28 days with figures ranging from 1 day to 400 days.

In the alopecia areata group, $84 \%$ of patients identified stressful events, compared to $56 \%$ of subjects in the control group $(\mathrm{p}=0.003)$.

Regarding the types of events mentioned, the most important matters in the alopecia areata group were related to personal problems (54\% of stressful situations) $(\mathrm{p}=0.015)$ and financial problems ( $44 \%$ of stressful situations) $(\mathrm{p}=0.010)$.

There was no significant statistical difference $(\mathrm{p}=0.30)$ between men and women (stress involvement in $48 \%$ of female cases and $52 \%$ of male cases.

Among personal and financial problems, the most often noted were personal illness and change in economic status in the alopecia areata group.
In patient group, women described more personal problems than men $(p=0.050)$ and men described more financial problems $(\mathrm{p}=0.003)$ as shown in tablel.

\section{DISCUSSION}

Several studies [11-13], assessing stressful life events have been conducted and seem to confirm that stress may exacerbate or trigger skin diseases. The early onset of alopecia areata was associated more frequently with psychological factors, such as stress, in $5 \%$ to $96 \%$ of cases.

Our study suggests the importance of stressful events as a precipitating or aggravating factor in $84 \%$ alopecia areata patients. There was statistically significant difference between patients and controls $(\mathrm{p}=0.003)$. Many studies $[14,15]$ which measured the frequency and number of stressful life events occurring over a specified period among alopecia areata suggested that such patients endured a significantly higher number of stressful life events than do controls suggesting that psychological distress may have contributed to the onset of alopecia areata.

Personal problems were more noted by women $(p=0.050)$ and financial ones were more cited by men $(p=0.003)$. Potential stressful situations for alopecia areata were personal problems and family problems, particularly in women [14]. Other studies [16-18] showed that many patients experienced the death of a close friend or family member and separation. The significant difference between men and women could be explained by the role of gender in our Arab- Muslim society and the difference of adjustment to stressful events $[19,20]$.

As well as the impact of stressful life events, psychological vulnerability of the patient is another factor that could influence the onset of psychosomatic diseases. Many studies [21,22] described alopecia areata patients as having high reactivity to stress; these patients also had

Table 1: Comparison between Alopecia Areata group and control group regarding the types of events involved

\begin{tabular}{lcccccccc}
\hline $\begin{array}{l}\text { Types of } \\
\text { events }\end{array}$ & \multicolumn{2}{c}{ Patients } & & \multicolumn{2}{c}{ Controls } & & \multicolumn{2}{c}{$\mathbf{p}$} \\
\cline { 2 - 3 } $\begin{array}{l}\text { Family } \\
\text { problems }\end{array}$ & 5 & 16 & & 3 & 11 & & 0.701 & 0.165 \\
$\begin{array}{l}\text { Personal } \\
\text { problems }\end{array}$ & 10 & 17 & & 5 & 10 & & 0.050 & 0.119 \\
$\begin{array}{l}\text { Job/financial } \\
\text { problems }\end{array}$ & 15 & 7 & & 5 & 5 & & 0.510 & 0.003 \\
\hline
\end{tabular}


higher scores for depression. Some of the life situations listed by Holmes and Rahe are related to psychological characteristics of patients (family disputes, exams, different kinds of changes in activities, etc.). As we have not investigated any psychological vulnerability, we are unable to comment on the impact of an event in association with psychological traits.

\section{Limitations}

There are some limitations to our study that should be taken into consideration. First, the sample size was relatively small. Secondly, the participants were recruited from a hospital service of general dermatology. Consequently, our patient sample may not be representative of all patients with AA. We don't explore the importance of perceived stress, which is sometimes even more important than the stressful situation in some cases. This is the first Tunisian case control study on the subject.

\section{CONCLUSION}

The study confirms the relationship between alopecia areata and stressful events at the onset or before exacerbation. Personal and financial problems play an important role in alopecia areata. More studies are needed on this subject possibly taking into account stress perception.

\section{Statement of Human and Animal Rights}

All procedures followed were in accordance with the ethical standards of the responsible committee on human experimentation (institutional and national) and with the Helsinki Declaration of 1975 , as revised in 2008 .

\section{Statement of Informed Consent}

Informed consent was obtained from all patients for being included in the study.

\section{REFERENCES}

1. Simakou T, Butcher JP, Reid S, Henriquez FL. Alopecia areata: A multifactorial autoimmune condition. J Autoimmun. 2019;98:74-85.

2. Safavi K. Prevalence of alopecia areata in the First National Health and Nutrition Examination Survey. Arch Dermatol. 1992;128:702.
3. Yang CC, Chen CC, Chen WC. Aging and Anti-Aging in Hair and Hair Loss. Inflammation. Adv. Age Nutr. Res. Clin. Interv. 2013, Elsevier.

4. Assouly P. Pelade. Encycl Med Chir, Dermatologie. 2006;37- 400C-10: $p$,

5. Misery L, Rousset H. La pelade est-elle une maladie psychosomatique? Rev Méd Interne. 2001;22:274-9.

6. Gupta MA, Gupta AK, Wateel GN. Stress and alopecia areata:a psychodermatologic study. Acta Derm Venereol. 1997:77:296-8.

7. Picardi A, Abeni D. Stressful life events and skin diseases:disentangling evidence from myth. Psychother Psychosom. 2001;70:118-36.

8. Toyoda M, Makino T, Kagoura M, Morohashi M. Expression of neuropeptide-degrading enzymes in alopecia areata: an immunohistochemical study. Br-J-Dermatol. 2001;144:46-54.

9. Holmes TH, Rahe RH. The social readjustment rating scale. J Psychosom Res. 1967;11:213-8.

10. Olsen EA, Hordinsky MK, Price VH, Roberts JL, Shapiro J, Canfield D, et al. Alopecia areata investigational assessment guidelines - Part II. National Alopecia Areata Foundation. J Am Acad Dermatol. 2004;51:440-7.

11. Consoli SG, Chastaing M, Misery L. Psychiatrie et dermatologie. Encycl Med Chir, 2010;98-874-A-10:p.

12. Mulinari-Brenner F. Psychosomatic aspects of alopecia areata. Clin Dermatol. 2018;36:709-13.

13. Tordeurs D, Poot F, Janne P, Reynaert CH, Salamon V. Approche psychologique de différentes dermatoses: événements de vie et propension à se plaindre. Ann Dermatol Venereol. 2001;128:21-4.

14. Rajoo Y, Wong J, Cooper G, Raj IS, Castle DJ, Chong AH, et al. The relationship between physical activity levels and symptoms of depression, anxiety and stress in individuals with alopecia Areata. BMC Psychol. 2019;7:48.

15. Willemsen R, Vanderlinden J, Roseeuw D, Haentjens P. Increased history of childhood and lifetime traumatic events among adults with alopecia areata. J Am Acad Dermatol. 2009;60:388-93.

16. Panconesi E, Hautmann G. Psychopatology of stress in dermatology. Dermatol Clin. 1996;14:399-421.

17. Welsh N, Guy A. The lived experience of alopecia areata: a qualitative study. Body Image. 2009;6:194-200.

18. Leadbeater BJ, Blatt SJ, Quinlan DM. Gender-linked vulnerabilities to depressive symptoms, stress, and problem behaviors in adolescents. J Res Adoles. 1995;5:1-29.

19. Prie BE, Iosif L, Tivig I, Stoian I, Giurcaneanu C. Oxidative stress in androgenetic alopecia. J Med Life. 2016;9:79-83.

20. Azzawi S, Penzi LR, Senna MM. immune privilege collapse and alopecia development: is stress a factor. Skin Appendage Disord. 2018;4:236-44.

21. Rushdy OH, Mohammad NS, Kamha ES, Omar M. Genetic analysis of $5 \alpha$ reductase type 2 enzyme in relation to oxidative stress in cases of androgenetic alopecia in a sample of egyptian population. Our Dermatol Online. 2013;4:468-74.

22. Vélez-Muñiz RDC, Peralta-Pedrero ML, Jurado-Santa Cruz F, Morales-Sánchez MA. Psychological Profile and Quality of Life of Patients with Alopecia Areata. Skin Appendage Disord. 2019;5:293-8.

Copyright by Rim Sellami, et al. This is an open-access article distributed under the terms of the Creative Commons Attribution License, which permits unrestricted use, distribution, and reproduction in any medium, provided the original author and source are credited.

Source of Support: Nil, Conflict of Interest: None declared. 